\title{
Hubungan antara Status Kebersihan Mulut dengan Karies Siswa Sekolah Menengah Atas Negeri 1 Manado
}

\author{
${ }^{1}$ A. J. M. Rattu, ${ }^{2}$ Dinar Wicaksono, ${ }^{3}$ Virginia E. Wowor \\ ${ }^{1}$ Dosen di Fakultas Kedokteran,Universitas Sam Ratulangi \\ ${ }^{2}$ Dosen di Program Studi Kedokteran Gigi, Fakultas Kedokteran, Universitas Sam \\ Ratulangi \\ ${ }^{3}$ Mahasiswa Program Studi Kedokteran Gigi, Fakultas Kedokteran, Universitas Sam \\ Ratulangi
}

\begin{abstract}
ABSTRAK
Masalah kesehatan gigi dan mulut terbesar yang umum dihadapi yaitu karies. Karies merupakan penyakit universal yang dapat terjadi pada semua usia, ras, sosial-ekonomi dan jenis kelamin. Salah satu faktor penting penyebab terjadinya karies yaitu kurangnya menjaga kebersihan gigi dan mulut.Nilai kebersihan gigi dan mulut penting untuk diketahui tiap individu, hal tersebut berperan dalam upaya pencegahan terhadap terjadinya karies.Status kebersihan mulut dan karies dinilai dengan menggunakan indeks OHI-S dan DMF-T menurut WHO.Penelitian ini bersifat deskriptif analitik dengan menggunakan pendekatan cross sectional dan dilakukan pada siswa Sekolah Menengah Atas Negeri 1 Manado kelas X yang pada umumnya merupakan kelompok remaja umur 14-15 tahun dengan jumlah sampel sebanyak 83 siswa. Teknik pengambilan sampel menggunakan proportional random sampling. Hasil penelitian dianalisis secara univariat dan bivariat dengan menggunakan program SPSS 20. Hasil penelitian menunjukkan indeks OHI-S rata-rata sebesar 1,6 dalam kategori WHO termasuk sedang dan DMF-T rata-rata sebesar 4,6 dalam kategori WHO termasuk tinggi. Berdasarkan hasil uji chisquare menggunakan program SPSS 20 didapatkan $\mathrm{p}$ value 0,117 ( $>>0,005)$.Berdasarkan hasil tersebut, dapat disimpulkan status kebersihan gigi dan mulut termasuk kategori sedang dan status karies termasuk kategori tinggi dan tidak terdapat hubungan yang bermakna antara status kebersihan gigi dan mulut dengan karies siswa SMA Negeri 1 Manado.
\end{abstract}

Kata kunci:Kebersihan gigi dan mulut, Karies

\begin{abstract}
Oral health problems most commonly faced by caries. Caries is a universal disease that can occur at any age, ethnic, socio-economic and gender. One important factor is the lack of cause of caries and oral hygiene. Value of oral hygiene is important to know the individual, it contributes to the prevention of caries. Oral hygiene and caries status was assessed by using an index OHI-S and DMF-T according to the WHO.This is a descriptive analytic study using cross-sectional approach and performed in high school students of class $X$ in SMA Negeri 1 Manado which is generally a group of adolescents aged 14-15 years with a total sample of 83 students. Sampling technique using proportional random sampling. The results were analyzed using univariate and bivariate using SPSS 20.The results showed OHI-S index by an average of 1.6 in the WHO category includes medium and DMF-T by an average of 4.6 in the high category, including WHO. Based on the results of the chi-square test using SPSS 20 obtained $p$ value 0.117 ( $p>0.005)$. Based on these results, we can conclude the status of oral hygiene including medium category and caries status were high and there was no significant association between oral hygiene status with caries students of SMA Negeri 1 Manado.
\end{abstract}

Keywords :Oral hygiene, Caries 
Korespondensi: Virginia Eucharisty Wowor. Program Studi kedokteran Gigi. Fakultas Kedokteran Universitas Sam Ratulangi, Manado, Indonesia. E-mail: virginiaeucharisty@ymail.com

\section{PENDAHULUAN}

Kesehatan gigi dan mulut merupakan bagian integral dari kesehatan secara keseluruhan yang dapat memengaruhi kualitas hidup seseorang dan menjadi perhatian penting dalam pembangunan kesehatan penduduk Indonesia maupun negara-negara berkembang lainnya. ${ }^{1,2}$ Masalah kesehatan gigi dan mulut terbesar yang umum dihadapi yaitu karies. Karies merupakan penyakit universal yang dapat terjadi pada semua usia, ras, sosial-ekonomi, dan jenis kelamin. Berdasarkan data World Health Organisation (WHO) tahun 2012, di seluruh dunia $60-90 \%$ anak-anak sekolah dan hampir $100 \%$ orang dewasa memiliki karies yang sering menimbulkan rasa sakit serta dapat memengaruhi kualitas hidup. ${ }^{1,3,4}$

Berdasarkan hasil Survei Riset Kesehatan dasar (Riskesdas) Nasional tahun 2007 menunjukkan indeks Decayed Missing Filled Tooth (DMF-T) sebagai indikator status kesehatan gigi, yaitu sebesar 4,85. Hal ini menunjukkan banyaknya kerusakan gigi pada penduduk Indonesia yaitu 5 buah gigi per orang, dan prevalensi penduduk Indonesia yang mengalami karies gigi sebesar 72,1\%. Provinsi Sulawesi Utara menempati urutan ketiga prevalensi karies aktif yaitu sebesar 57,2\%. ${ }^{5}$

Salah satu faktor penting penyebab terjadinya karies yaitu kurangnya menjaga kebersihan gigi dan mulut.Kebersihan gigi dan mulut dapat dinilai dengan menggunakan Oral Hygiene Index Simplified (OHI-S) Green and vermillion dengan menjumlahkan Debris Index (DI) dan Calculus Index (CI). Nilai kebersihan gigi dan mulut penting untuk diketahui tiap individu, hal tersebut berperan dalam upaya pencegahan terhadap terjadinya karies. ${ }^{6}$,
Seperlima dari populasi dunia ialah remaja, didefinisikan oleh WHO sebagai kelompok usia 10 sampai 19 tahun yang merupakan kelompok sasaran penting untuk pembangunan kesehatan gigi dan mulut. ${ }^{8} \mathrm{WHO}$ merekomendasikan kelompok umur tertentu untuk dilakukan pemeriksaan, umur 15 tahun dianggap sebagai umur dimana gigi permanen sudah terekspos dengan lingkungan mulut selama 3-9 tahun, sehingga pemeriksaan karies gigi dianggap lebih bermakna dibandingkan pada umur 12 tahun. $^{2,9}$

Prevalensi karies yang tinggi dan keterkaitan kebersihan gigi dan mulut dengan terjadinya karies pada usia remaja semakin banyak diteliti oleh negara-negara berkembang. Laporan penelitian di Indonesia mengenai status karies dan kebersihan mulut masih kurang diteliti pada kelompok usia remaja khususnya usia 14-15 tahun, penelitian tersebut diperlukan sebagai indikator untuk menilai keadaan kesehatan gigi serta keberhasilan upaya kesehatan gigi dan mulut.

Penelitian ini dilakukan pada siswa Sekolah Menengah Atas (SMA) Negeri 1 Manado kelas $\mathrm{X}$ yang merupakan kelompok usia 14-15 tahun, pada survei awal diketahui bahwa SMA Negeri 1 Manado merupakan salah satu sekolah favorit dengan jumlah siswa terbanyak di kota Manado dengan karakteristik siswa yang beragam dan belum pernah dilakukan penelitian tentang status karies dan kebersihan mulut di sekolah tersebut. Berdasarkan latar belakang yang telah diuraikan, maka penulis tertarik untuk meneliti hubungan antara status kebersihan mulut dengan karies siswa SMA Negeri 1 Manado. 


\section{METODE PENELITIAN}

Jenis penelitian yang digunakan ialah penelitian deskriptif analitik dengan desain cross-sectional.Penelitian ini dilakukan pada bulan Agustus 2013 diSMA Negeri 1 Manado.

Populasi target ialah seluruh siswa kelas $X$ SMA Negeri 1 Manado usia 14-15 tahun.Berdasarkan survei awal, siswa kelas X berjumlah 486 siswa.Besar sampel diperoleh dengan menggunakan rumus perhitungan besar sampel oleh Slovin dan didapatkan hasil 83 sampel.Sampel ialah yang memenuhi kriteria inklusi yaitu sehat secara jasmani, bersedia dengan sukarela untuk dijadikan subjek dalam penelitian, bersifat kooperatif danhadir saat dilakukan penelitian.Kriteria eksklusi yaitu siswa-siswi yang tidak bersedia untuk dilakukan pemeriksaan dalam rongga mulutnya, bersifat non kooperatif dalam pengambilan data dan tidak hadir pada saat dilakukan penelitian.

Teknik pengambilan sampel yang digunakan yaitu proportional random sampling.Proporsi sampel dalam penelitian ini ialah perbandingan jumlah sampel yang disebut dengan sampel fraction (SF) dengan jumlah populasi. Berdasarkan rumus tersebut, jumlah sampel disetiap kelas diambil sebanyak $17 \%$ dari jumlah populasi yang ada.

Variabel yang diteliti dalam penelitian ini yaitu status kebersihan gigi dan mulut (Indeks OHI-S), status karies (Indeks DMF-T) dan remaja siswa SMA.Data primer berupa data DMF-T dan OHI-S diperoleh dengan melakukan pemeriksaan langsung di dalam rongga mulut menggunakan kaca mulut dan sonde dan hasil pemeriksaan dicatat langsung pada lembar pemeriksaan. Data sekunder yang berkaitan dengan identitas siswa diperoleh dengan wawancara langsung oleh peneliti.
Analisis data yang digunakan ialah analisis univariat dan bivariat.Data diolah dengan sistem SPSS versi 20 dan diuji dengan menggunakan uji chi square.

Dalam penelitian ini uji signifikandilakukan dengan menggunakan batas kemaknaan alpha $(\alpha)=0,05$ dan $95 \%$ confidence interfal. Data disajikan berdasarkan distribusi frekuensi dalam bentuk diagram dan tabel.

\section{HASIL PENELITIAN}

Gambar 1. Diagram distribusi karakteristik subjek penelitian berdasarkan jenis kelamin

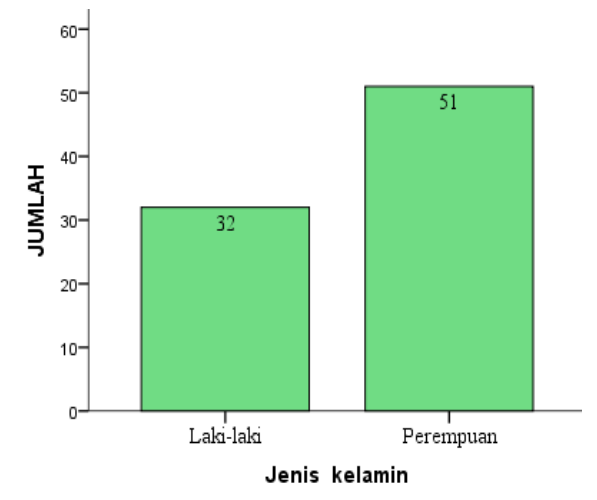

Gambar 2. Diagram distribusikarakteristik subjek penelitian berdasarkan umur

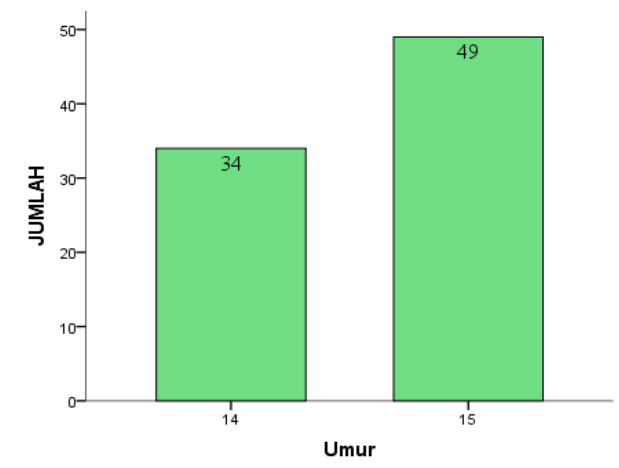


Gambar 3. Diagram distribusi status kebersihan mulut berdasarkan OHI-S

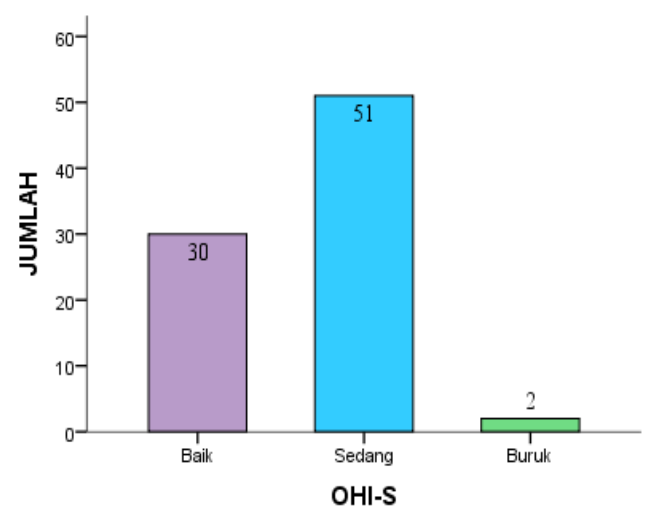

Gambar 4. Diagram distribusi status kebersihan mulut berdasarkan jenis kelamin

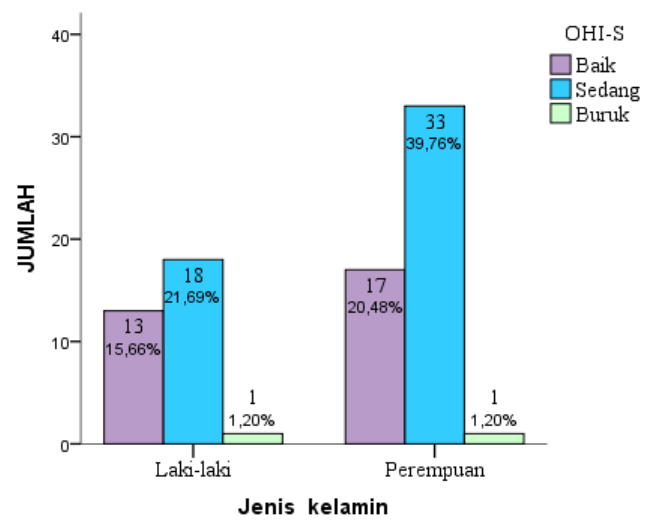

Gambar 5. Diagram distribusi status karies berdasarkan DMF-T

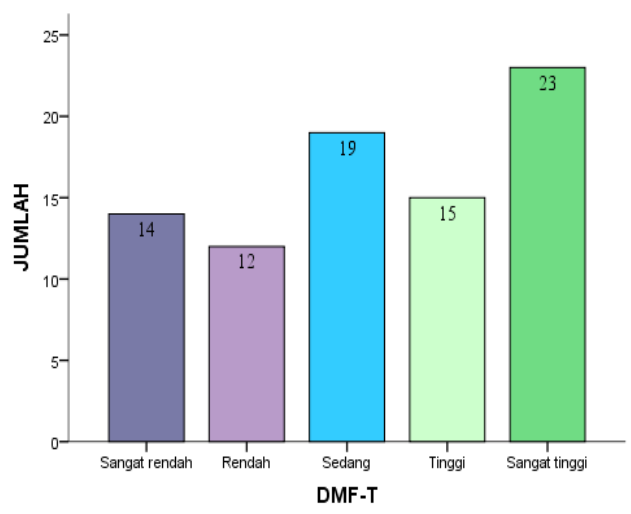

Gambar 6. Diagram distribusi status karies berdasarkan jenis kelamin

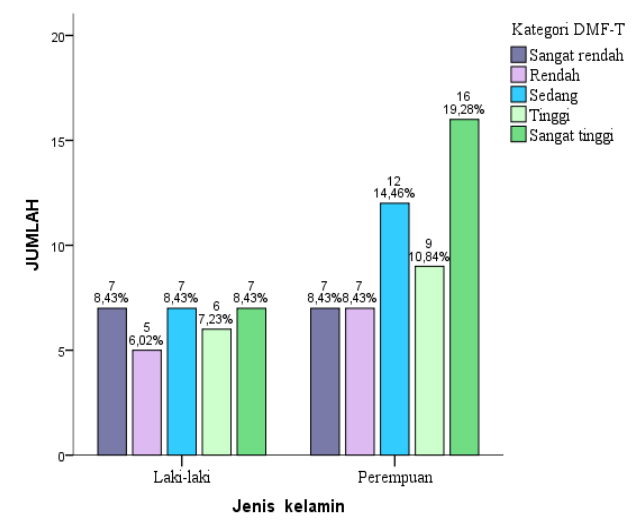

Tabel 1. Hasil analisis hubungan status kebersihan mulut dengan karies

\begin{tabular}{|c|c|c|c|c|c|c|c|c|}
\hline \multirow[b]{2}{*}{ OHI-S } & & \multicolumn{5}{|c|}{ DMF-T } & \multirow[b]{2}{*}{ Total } & \multirow[b]{2}{*}{$\begin{array}{c}\mathrm{p} \\
\text { value }\end{array}$} \\
\hline & & $\begin{array}{l}\text { Sangat } \\
\text { rendah }\end{array}$ & Rendah & Sedang & Tinggi & $\begin{array}{l}\text { Sangat } \\
\text { tinggi }\end{array}$ & & \\
\hline \multirow{2}{*}{ Baik } & $\mathrm{n}$ & 9 & 5 & 7 & 5 & 4 & 30 & \multirow{8}{*}{0,117} \\
\hline & $\%$ & $10,8 \%$ & $6 \%$ & $8,4 \%$ & $6 \%$ & $4,8 \%$ & $36,1 \%$ & \\
\hline \multirow{2}{*}{ Sedang } & $\mathrm{n}$ & 5 & 7 & 12 & 10 & 17 & 51 & \\
\hline & $\%$ & $6 \%$ & $8,4 \%$ & $14,5 \%$ & $12 \%$ & $20,5 \%$ & $61,4 \%$ & \\
\hline \multirow{2}{*}{ Buruk } & $\mathrm{n}$ & 0 & 0 & 0 & 0 & 2 & 2 & \\
\hline & $\%$ & 0 & 0 & 0 & 0 & $2,4 \%$ & $2,4 \%$ & \\
\hline \multirow{2}{*}{ Total } & $\mathrm{n}$ & 14 & 12 & 19 & 15 & 23 & 83 & \\
\hline & $\%$ & $16,9 \%$ & $14,5 \%$ & $22,9 \%$ & $18,1 \%$ & $27,7 \%$ & $100 \%$ & \\
\hline
\end{tabular}




\section{PEMBAHASAN}

Subjek pada penelitian ini berjumlah 83 siswa dengan karakteristik dikelompokkan berdasarkan jenis kelamin dan umur. Jumlah siswa lakilaki sebanyak 32 siswa $(38,6 \%)$ dan perempuan sebanyak 51 siswa $(61,4 \%)$ (Gambar 1).Distribusi subjek penelitian berdasarkan umur 14 dan 15 tahun menunjukkan jumlah siswa umur 14 tahun sebanyak 34 siswa (41\%) dan jumlah siswa umur 15 tahun sebanyak 49 siswa (59\%) (Gambar 2).

Data pada gambar 3 menunjukkan hasil penelitian status kebersihan mulut sebanyak 30 siswa $(36,1 \%)$ memiliki kategori baik, 51 siswa $(61,4 \%)$ memiliki kategori sedang, dan 2 siswa $(2,4 \%)$ memilliki kategori buruk. OHI-S rata-rata yaitu 1,6 yang dalam indeks karies menurut WHO termasuk dalam kategori sedang. Hal ini juga didukung oleh penelitian di Yunani pada remaja usia 15 tahun yang menunjukkan nilai indeks kebersihan gigi dengan kategori sedang. ${ }^{10}$ Penelitian yang hampir sama di Kuwait pada usia 5-14 tahun 3,9\% memiliki kategori baik, $67 \%$ sedang dan $29,1 \%$ termasuk dalam kategori buruk dan nilai OHI-S rata-rata yaitu 1,5 merupakan kategori sedang. ${ }^{11}$ Hasil penelitian pada siswa SMA Negeri 1 Manado menunjukkan bahwa masih rendahnya persentase kebersihan gigi dan mulut dengan kategori baik dan persentase tertinggi pada kategori sedang menunjukkan pada umumnya sebagian siswa sudah bisa menjaga kebersihan mulutnya, namun perlu lebih ditingkatkan kesadaran dan tindakan akan pemeliharaan kebersihan mulut.

Data pada gambar 4 menunjukkan subjek penelitian dengan jenis kelamin laki-laki sebanyak 13 siswa $(15,66 \%)$ kategori baik, 18 siswa $(21,69 \%)$ kategori sedang, dan 1 siswa $(1,20 \%)$ laki-laki memiliki kategori buruk. Subjek penelitian dengan jenis kelamin perempuan sebanyak 17 siswa $(20,48 \%)$ kategori baik, 33 siswa $(39,76 \%)$ kategori sedang, dan 1 siswa $(1,20 \%)$ kategori buruk.Penilaian OHI-S pada siswa laki-laki dan perempuan menunjukkan nilai status kebersihan gigi dan mulut dengan perbandingan yang hampir sama, akan tetapi siswa laki-laki memiliki nilai OHI-S rata-rata yang lebih tinggi yaitu 1,6 dibandingkan perempuan yang memiliki nilai $\mathrm{OHI}-\mathrm{S}$ rata-rata 1,5. Hasil penelitian di Kuwait juga menunjukkan nilai indeks OHI-S yang tidak jauh berbeda, nilai OHI-S lebih tinggi untuk anak laki-laki dibandingkan anak perempuan (rata-rata skor 1,6 banding 1,5). ${ }^{11}$ Hal ini sama dengan penelitian-penelitian pada remaja yang dilakukan di Jepang, Uganda dan Kenya yang menyatakan bahwa perilaku perawatan kesehatan gigi dan mulut anak perempuan lebih baik dari pada anak laki-laki. ${ }^{12,13,14}$ Pada penelitian ini, umumnya yang lebih tertarik untuk dilakukan pemeriksaan yaitu kelompok remaja perempuan, dapat dilihat dari jumlah perempuan yang mendominasi dan sangat antusias untuk dilakukan pemeriksaan saat penelitian. Anak perempuan lebih baik dalam perilaku menjaga kebersihan mulut dibandingkan anak laki-laki, hal ini disebabkan anak perempuan lebih mementingkan dan memiliki kesadaran yang tinggi akan estetik dan pemeliharaan kebersihan giginya sehingga akan lebih rajin untuk menyikat gigi. Gigi yang terlihat baik sangat menunjang penampilan dan meningkatkan kepercayaan diri bagi perempuan.

Data pada gambar 5 menunjukkan hasil pemeriksaan DMF-T pada 83 subjek penelitian dengan hasil terdapat 14 siswa $(16,9 \%)$ kategori sangat rendah, 12 siswa $(14,5 \%)$ kategori rendah, 19 siswa $(22,9 \%)$ kategori sedang, 15 siswa $(18,1 \%)$ kategori tinggi dan 23 siswa $(27,7 \%)$ dengan kategori sangat tinggi.DMF-T rata-rata sebesar 4,6 yang berdasarkan kategori indeks karies 
menurut WHO termasuk dalam kategori tinggi. Hal ini didukung dengan penelitian di Brazil, dan Iran pada anak usia 14 dan 15 tahun menunjukkan nilai status karies dengan kategori DMF-T tinggi. ${ }^{15,16}$ Hasil penelitian menunjukkan bahwa masih terdapat kekurangan dalam bidang perawatan gigi baik preventif dan kuratif. Hal tersebut dapat disebabkan karena pada masa remaja cenderung membiarkan keadaan giginya yang terserang karies bila tidak ada rasa sakit dan tidak langsung ke dokter gigi, hal tersebut dapat dilihat dalam hasil $\mathrm{F}$ (Filling) dalam DMF-T yang cenderung kurang dan pada masa ini remaja cenderung tidak lagi dibantu oleh orang tua untuk pemilihan makanan bisa saja asupan makanan memengaruhi peningkatan terjadinya karies. Peningkatan program pendidikan kesehatan gigi dan mulut lewat penyuluhan dan pendekatan berbasis sekolah serta program pencegahan kepada masyarakat khususnya keluarga haruslah lebih ditingkatkan.

Data pada gambar 6 menunjukkan hasil pemeriksaan DMF-T berdasarkan jenis kelamin pada 83 subjek penelitian. Jenis kelamin laki-laki sebanyak 7 siswa $(8,43 \%)$ kategori sangat rendah, 5 siswa $(6,02 \%)$ kategori rendah, 7 siswa $(8,43 \%)$ kategori sedang, 6 siswa $(7,23 \%)$ kategori tinggi dan 7 siswa $(8,43 \%)$ dengan kategori sangat tinggi. Jenis kelamin perempuan sebanyak 7 siswa $(8,43 \%)$ kategori sangat rendah, 7 siswa $(8,43 \%)$ kategori rendah, 12 siswa $(14,46 \%)$ kategori sedang, 9 siswa $(10,84 \%)$ kategori tinggi dan 16 siswa $(19,28 \%)$ kategori sangat tinggi.Hasil pemeriksaan karies berdasarkan jenis kelamin. Jenis kelamin laki-laki memiliki DMF-T rata-rata 4,4 kategori sedang. Jenis kelamin perempuan memiliki DMF-T rata-rata 4,8 kategori tinggi. Wanita memiliki DMF-T yang lebih tinggi dibandingkan dengan pria, dalam penelitian pada siswa umur 8-12 tahun dikemukakan bahwa erupsi gigi wanita terjadi lebih awal dibandingkan dengan pria, sehingga gigi telah terkontaminasi lebih lama dalam rongga mulut. ${ }^{17}$ Penelitian oleh satima A, Saleem M mengemukakan perempuan lebih tinggi DMF-T disebabkan oleh perilaku pemeliharaan dan asupan makanan, ${ }^{18}$ berbeda dengan penelitian oleh Hamissi yang mendapatkan hasil siswa laki-laki memiliki nilai DMF-T rata-rata tinggi $(2,88 \pm 0,61)$ dibandingkan dengan siswa perempuan . $(2,54 \pm 0.71) .{ }^{16}$ Penelitian yang dilakukan oleh Lucaks dan Largaespada, terdapat perbedaan angka karies pada jenis kelamin laki-laki dan perempuan dikaitkan dengan faktor hormonal, dimana perempuan memiliki hormon estrogen yang meningkat pada siklus menstruasi, kehamilan, dan pubertas. Seiring meningkatnya hormon estrogen maka angka kariespun meningkat. ${ }^{19}$ Penulis berasumsi bahwa pengaruh hormonal, asupan makanan dan erupsi gigi yang lebih awal pada perempuan yang menjadikan prevalensi karies lebih tinggi pada perempuan dibandingkan laki-laki.

Data pada tabel 1 menunjukkan hasil analisis chi square tentang hubungan status kebersihan mulut dengan karies didapatkan $\mathrm{p}$ value $0,117(\mathrm{p}>\alpha)$, maka dapat disimpulkan bahwa Ho diterima. Jadi, tidak terdapat hubungan yang signifikan antara status kebersihan mulut dengan karies siswa SMA Negeri 1 Manado.Hasil penelitian didukung juga oleh penelitian tahun 2008 mengenai hubungan karies dengan status kebersihan mulut dan faktor resiko ekstra oral oleh Rehman MM, Mahmood N, Rehman B yang menunjukkan tidak terdapat hubungan antara status kebersihan mulut dengan karies pada remaja. ${ }^{20}$ Penelitian di Nepal juga mengemukakan bahwa tidak terdapat hubungan antara status kebersihan gigi dan mulut dengan karies pada remaja usia 12, 13 dan 15 tahun, dalam penelitian ini dikemukakan bahwa 
remaja memiliki kebersihan mulut yang buruk tapi relatif bebas dari karies selama konsumsi gula harian rendah, setelah konsumsi gula harian dan karbohidrat olahan meningkat terjadi peningkatan yang sesuai pada karies gigi. ${ }^{21}$ Dalam laporan pencegahan karies di Kanada mengemukakan bahwa prosedur kebersihan mulut yang terdiri dari penghapusan plak dengan menyikat gigi dan flossing tidak menyebabkan pengurangan karies. Penghapusan plak harian dianjurkan dalam kepentingan mengendalikan penyakit gingiva atau periodontal. ${ }^{22}$

Berbeda dengan penelitian di Pakistan yang menyimpulkan bahwa karies dapat dicegah dengan penghapusan plak. ${ }^{22}$ Penelitian yang dilakukan di Sulawesi Selatan pada siswa SMA usia 15-16 tahun menunjukkan terdapat hubungan antara OHI-S dengan terjadinya karies. ${ }^{23}$ Penelitian-penelitian yang menunjukkan hasil hubungan antara status kebersihan mulut dengan karies menjadi bagian yang kontroversial karena beberapa peneliti telah menyimpulkan bahwa kebersihan mulut merupakan faktor risiko untuk karies, sementara yang lain tidak menemukan hal tersebut. ${ }^{24}$

Penelitian lain yang juga mendukung penelitian ini yaitu penelitian yang dilakukan oleh Stephan yang mengatakan bahwa setelah mengkonsumsi karbohidrat maka $\mathrm{pH}$ mulut akan turun dalam 5-10 menit menjadi 5,5 yang bersifat asam, tetapi akan normal kembali dalam waktu 3045 menit, ${ }^{25}$ dengan penambahan sukrosa dalam bentuk minuman, roti, coklat, karamel dan permen di antara waktu makan dapat menyebabkan meningkatnya aktivitas karies tetapi apabila dikonsumsi di waktu makan saja maka kecepatan pembentukan akan berkurang bahkan tidak terbentuk karies. ${ }^{26}$ Tingkat konsumsi gula telah meningkat secara keseluruhan di negara berkembang, peningkatan prevalensi karies gigi dalam negara berkembang telah dianggap berasal dari peningkatan konsumsi gula. ${ }^{24}$ Penelitian crosssectional dan prospektifjuga telah menunjukkan hubungan yang lemah antara plak dan karies gigi dan ini menyebabkan beberapa pertentangan dari nilai intrinsik praktek kebersihan mulut dalam pencegahan karies gigi. ${ }^{22}$

Penulis berasumsi bahwa tidak terdapat hubungan antara kebersihan mulut dengan karies disebabkan karena pada usia remaja, kelompok usia ini cenderung mulai mandiri, memperhatikan keadaaan dirinya sendiri dan mengatur sendiri kehidupannya sehingga perilaku untuk kebersihan gigi dan mulut telah dipraktekkan dalam kehidupan sehari-hari dari masingmasing individu.

Pada usia ini, remaja mulai memutuskan sendiri apa yang akan dia makan tanpa bergantung lagi pada orang tua dan cenderung lapar di antara waktu makan. Remaja sangat tertarik untuk mengkonsumsi cemilan yang mengandung gula contohnya coklat, permen, dan minuman berkarbonasi di antara waktu makan sehingga hal tersebut memicu peningkatan terjadinya karies. Keberadaan makanan manis, makanan ringan dan minuman berkarbonasi di dalam dan di luar kompleks sekolah telah menjangkau kalangan siswa untuk membeli dan mengkonsumsinya, hal ini juga didukung dengan ketertarikan remaja pada usia ini yang tampaknya lebih tertarik dengan rasa dan penampilan makanan dari pada nilai gizi.

Mengontrol konsumsi gula dan ketersediaan serta keterjangkauan pasta gigi yang mengandung fluor menjadi faktor penting dalam pencegahan karies dari pada kebersihan mulut. Pendidikan kesehatan mulut harus menekankan menyikat gigi dua kali sehari dengan pasta gigi yang mengandung fluor dan 
mengurangi frekuensi konsumsi gula di antara waktu makan. ${ }^{21}$

\section{KESIMPULAN}

Berdasarkan penelitian pada siswa SMA Negeri 1 Manando dapat disimpulkan bahwa status kebersihan gigi dan mulut siswa dalam indeks OHI$\mathrm{S}$ menurut WHO termasuk kategori sedang. Status kebersihan gigi dan mulut berdasarkan jenis kelamin, siswa lakilaki dan siswa perempuan dalam indeks OHI-S menurut WHO termasuk kategori sedang. Status karies siswa dalam kategori indeks DMF-T menurut WHO termasuk kategori tinggi. Status karies berdasarkan jenis kelamin, siswa lakilaki dalam indeks DMF-T menurut WHO termasuk kategori tinggi dan siswa perempuan termasuk kategori sangat tinggi.Tidak terdapat hubungan yang signifikan antara status kebersihan mulut dengan karies.

\section{SARAN}

Berdasarkan penelitian ini disarankan kepada Dinas Kesehatan untuk lebih memerhatikan derajat kesehatan gigi dan mulut pada kelompok usia remaja dengan meningkatkan program kesehatan gigi dan mulut, serta penyediaan sarana dan prasarana untuk menunjang pelaksanaan program tersebut.Diharapkan bagi sekolah agar lebih meningkatkan peran UKGS dan memotivasi siswa SMA dalam pemeliharaan kesehatan gigi dan mulut.Pihak sekolah diharapkan bekerjasama dengan Dinas Kesehatan dalam upaya peningkatan derajat kesehatan gigi dan mulut. Diharapkan juga untuk dapatdilakukan penelitian lebih lanjut dan meluas mengenai kesehatan gigi dan mulut pada kelompok usia remaja.

\section{DAFTAR PUSTAKA}

1. British Dental Journal. Dental caries a global health problem.[online]. 2004[cited 2013 July].Available from: URL : http://www.nature.com/bdj/journal/ v196/n5/full/4811108a.html

2. Hiremath SS. Textbook of preventive and community dentistry. New Delhi: Elsevier; 2007.p. 122, 176, 184, 194$195,384,300,302$

3. Gupta FP. Differential diagnosis of dental disease. 1st ed. India: Jaypee; 2008.p.118

4. World Health Organisation. Media centre oral health. [online]. April 2012 .Available from: http://www.who.int/mediacentre/fa ctsheets/fs318/en/

5. Badan Peneliti dan Pengembangan Kesehatan Republik Indonesia. Laporan hasil riset kesehatan dasar nasional 2007. Jakarta: Departemen Kesehatan RI. 2008. hal. 129-146.

6. Chandra S, Saleen C, Girish C. Textbook of operative dentistry. 1st ed. New Delhi: Jaypee; 2007. p. 29, 31, 33, 37.47

7. Darby ML, Walsh M. Dental hygiene: theory and practice. 3rd ed. St Louis: Saunders; 2010

8. World Health Organisation. Important target group. [online]. 2013. Available from: URL:http://www.who.int/oral healt h/action/groups/en/

9. Sondang P, Harmada T. Menuju gigi dan mulut sehat, pencegahan dan pemeliharaan. Medan: USU Press. 2008. hal. 1-34. Available from: URL: http://usupress.usu.ac.id/files/Menu ju\%20Gigi\%20dan\%20Mulut\%20S ehat\%20_Pencegahan\%20dan\%20P emeliharaan_Normal_bab\%201.pd f

10. VadiakasG, Oulis CJ, Tsinidou K, Mamai H.E. Oral hygiene and periodontal status of 12 and 15 years old greek adolescents. A national pathfinder survey. Eur Arch Paediatr Dent[online]. 2012; 13(1): 11-20. Available from: URL: 
http://www.ncbi.nlm.nih.gov/pubm ed/22293100

11. Mutawa S.A, Shyamma M, Duwairi Y, Soparkar P. Oral hygiene status of Kuwaiti schoolchildren. 2011; 17(5): 387-391. Available from:URL:

http://applications.emro.who.int/em hj/V17/05/17_5_2011_0387_0391. pdf

12. Kawamura M, Takase N, Sasahara H, Okada M. Teenagers oral health attitudes and behaviour in Japan: Comparison by sex and age group. 2008 Journal of Oral science, Vol 50, No.2, p. 167-74. Available from:

URL: http://www.ncbi.nlm.nih.gov/pubm ed/18587206

13. Okullo A, Haugejorden O. Social inequalities in oral health and in use of oral health care services among adolescents in Uganda. International Journal of Paediatric Dentistry.2004(14):326-35).

Available from: URL: http://www.ncbi.nlm.nih.gov/pubm ed/15330998

14. Kemwa KA GP, Rotich JK. The oral health knowledge and oral hygiene practices among primary school children age 5-17 years in a rural area of Uasin Gishu district, Kenya. East African Journal of Public Health. 2010;7(2):187-90. Available from: URL: http://www.ncbi.nlm.nih.gov/pubm ed/21413602

15. Goes PSA, Watt RG, Hardy R, Sheiham A. The prevalence and severity of dental pain in 14-15year-old Brazilian schoolchildren. Community Dental Health.2007; 24(4). Available from: URL: http://www.cdhjournal.org/view.ph p?article_id=124\&journal_id=6

16. Hamissi J, Ramezani G H, Ghodousi A. Prevalence of dental caries among high school attendees in Qazvin, Iran. J Indian Soc Pedod
Prev Dent [serial online] 2008 [cited 2013 Sep 24]; 26:53-5. Available from: URL: http://www.jisppd.com/text.asp?20 08/26/6/53/43532

17. Rai B, Jain R, Duhan J, Anand S. Relationship between dental caries and oral hygiene status of 8 to 12 years old school children. The Internet Journal of Epidemiology. 2006; 4(1). Available from: URL: http://ispub.com/IJE/4/1/8645

18. Saima A, Saleem M, Mohtada H, Fatima I. Distribution of dental caries and its relationship to risk factors. Pakistan oral \& dental journal. 2011: 31(2): 453-456. Available from: URL: http://www.podj.com.pk/Dec_2011/ 52-Podj.pdf

19. Lucaks JR, Largaespada LL. Explaining sex differences in dental caries prevalence: saliva, hormones, and "life history" etiologies. Am J of human Biology [serial online] 2006 [cited 2013 Sep 10]; 18: 54055. Available from: URL: http://pages.uoregon.edu/jrlukacs/D r.\%20John\%20R.\%20Lukacs\%20

Website/downloads/AJHB\%2018\% 20-\%202006.pdf)

20. Mohamed, Noha, Betul. The relationship of caries with oral hygiene status and extra oral risk factors. [online]. 2008; 20(1): 103108. Available from : URL: http://www.ayubmed.edu.pk/JAMC /PAST/20-1/Mustehsen.pdf

21. Yee R, David J, Khadka R. Oral cleanliness of 12-13-year-old and 15-year-old school children of Sunsari District, Nepal. J Indian Soc Pedod Prev Dent [serial online] 2006 [cited 2013 Sep 24]; 24: 14651. Available from: URL: http://www.jisppd.com/text.asp?20 06/24/3/146/27896)

22. Lewis DW, Ismail AI. Prevention of periodontal disease. The clinical guide to preventive health care, the 
Canadian task force on periodic health examination. Minister of supply and services: Ottawa. 2013.

Available from: URL:

http://canadiantaskforce.ca/guidelin es/all-guidelines/

23. Suyuti M. Hubungan faktor sosial ekonomi, perilaku dan oral hygiene terhadap karies gigi pada anak usia remaja umur 15-16 tahun di SMA Negeri 1 Galesong Utara. Jurnal ilmiah: 2013. Available from: URL: $\quad$ www.poltekkesmks.ac.id/index.php/tutorialsmainmenu-48/media-kesehatangigi/edisi-ke-1/672-hubunganfaktor-sosial-ekonomi-perilakudan-oral-hygiene-terhadap-kariesgigi-pada-anak-usia-remaja-umur15-16-tahun-di-sma-negeri-1galesong-utara

24. Nyamuryekung K. Health and oral health related knowledge, attitudes and behaviors- a study of secondary school students in Dar es Salaam, Tanzania A cross sectional study of 16-20 year old students.Centre for International Health and Department of Community Dentistry. $\quad$ Norway. 2012. Available from: URL:https://bora.uib.no/bitstream/h andle/1956/6187/94922681.pdf?seq uence $=1$

25. Workman J. Stephan Curve. Jamie the dentist[online]. 2012. Available from:

URL: http://jamiethedentist.com/dentalcaries-decay/stephan-curve

26. Kidd EAM, Beychal JS. Dasar dasar karies: penyakit dan penanggulangan. Jakarta: EGC; 2012.h. 1-17 